\title{
Effect of hypothyroidism on hormone profiles in virgin, pregnant and lactating rats, and on lactation
}

\author{
M. B. Hapon, M. Simoncini, G. Via and G. A. Jahn* \\ Laboratorio de Reproducción y Lactancia, IMBECU, CRICYT-CONICET, 5500 Mendoza, Argentina
}

Thyroid dysfunctions can produce reproductive problems. Untreated maternal hypothyroidism has serious consequences on development of offspring, resulting in stunted growth and mental retardation. The effects of propylthiouracyl-induced hypothyroidism $\left(0.1 \mathrm{~g} \mathrm{I}^{-1}\right.$ in drinking water starting 8 days before mating, or given to virgin rats for 30 or 50 days) on the serum profiles of hormones related to reproduction and mammary function (prolactin, growth hormone $(\mathrm{GH})$, progesterone, corticosterone, oestradiol, insulin-like growth factor I (IGF-I), thyroidstimulating hormone (TSH), triiodothyronine and tetraiodothyronine), and on mammary function in virgin, pregnant and lactating rats, were investigated. Propylthiouracyl treatment severely decreased circulating triiodothyronine and tetraiodothyronine concentrations, and increased serum TSH concentrations. Virgin rats showed prolonged periods of vaginal dioestrus, increased circulating progesterone concentrations and afternoon peaks of prolactin concentration, which are indicative of prolactin-induced pseudopregnancy. Propylthiouracyltreated virgin rats had mammary development comparable to that of midpregnancy, and half of these rats had increased mammary casein and lactose concentrations. Serum prolactin concentrations were decreased on the afternoon of day 5 of pregnancy, increased during late pregnancy (days 15-21) and were normal during lactation.
Circulating GH concentrations decreased on days 1521 of pregnancy, whereas progesterone concentrations increased during late pregnancy and early lactation. Circulating oestradiol (measured in late pregnancy and in virgin rats), IGF-I and corticosterone concentrations were decreased. Although assessment of mammary histology showed no differences in extent of development, casein content was increased in propylthiouracyl-treated rats on day 21 of pregnancy; litter growth was severely reduced and at day 20 of age the pups were hypothyroid, with decreased GH serum concentrations. An acute suckling experiment was performed on days 10-12 of lactation to determine whether some impairment in mammary function or the suckling reflex might account for these differences. After an $8 \mathrm{~h}$ separation of mothers from their litters and $30 \mathrm{~min}$ of suckling, circulating prolactin values were not affected by propylthiouracyl treatment, but serum oxytocin concentration and milk excretion were reduced. In conclusion, hypothyroidism induces various alterations in the hormone profiles of virgin and pregnant rats, and induces pseudopregnancies and mammary development in virgin rats. These alterations do not appear to have an overt impact on the outcome of pregnancy and on mammary function during lactation, with the exception of the milk ejection reflex, which may account at least partially for the reduced litter growth.

\section{Introduction}

The prevalence of hypothyroidism in women of childbearing age is relatively high and is associated with menstrual abnormalities, anovulation and hyperprolactinaemia in some cases (Peterson, 1994). The incidence of hypothyroidism during pregnancy has been calculated as between $0.3 \%$ and $0.7 \%$ (Glinoer, 1997), and there are certain associated risks, such as increased incidence of miscarriage, placental abruption and poor perinatal outcome with low birth weight (Becks and Burrow, 1991;

*Correspondence

Email: gjahn@lab.cricyt.edu.ar
Glinoer, 1997, 1998). Pregnancy is a state of dynamic changes in metabolism, with accumulation of lipids and nutrients during about the first half, whereas during late pregnancy and lactation these accumulated reserves are used for fetal growth and subsequently for milk synthesis. Thyroid hormones markedly influence these processes. Thyroid hormones also have documented actions on the secretion of hormones involved in reproduction and the maintenance of pregnancy. Thus, some of the harmful effects of hypothyroidism on pregnancy may be due to changes in the hormone balance rather than the direct effects of hypothyroidism on metabolism.

Pregnancy may be considered a state of functional hypothyroidism, as there are increased rates of plasma 
clearance for triiodothyronine and tetraiodothyronine (Versloot et al., 1994) owing to increased metabolism and excretion of free iodide from thyroid hormones in the liver and other peripheral tissues (Galton, 1968; Fukuda et al., 1980; Calvo et al., 1990). There may also be some generalized tissue resistance to thyroid hormones, as during late pregnancy and lactation there is a decrease in the peripheral deiodinases that transform tetraiodothyronine to its active form, triiodothyronine (Jack et al., 1994). At the same time, deiodinase activities increase in the mammary gland (Aceves and Valverde, 1989), favouring nutrient utilization and metabolism by the mammary tissue at the expense of the rest of the organism. Thus, a state of clinical or subclinical hypothyrodism may well be aggravated by the pregnant state, and the adequate function of the mammary glands may be compromised. The impact of maternal and neonatal hypothyroidism on the offspring is very well documented, and one of its most marked consequences is stunted growth and delayed maturation of the newborn that leads to mental retardation and subnormal height. Although most of these effects can be ascribed to the hypothyroid state of the infants, any alterations in maternal metabolism that could lead to decreased milk production or excretion could further complicate the prognosis for the offspring.

Hypothyroidism in rats results in decreased rates of ovulation, increased duration of gestation and fewer pups (Parrot et al., 1960; Hagino, 1971), but there are relatively few reports on the regulation of hormone secretion during pregnancy and lactation in the hypothyroid state, and of its consequences on mammary function.

In the present study, the effects of hypothyroidism during pregnancy and lactation on serum hormonal parameters were examined, particularly those hormones related to mammary growth and function, such as prolactin, progesterone, corticosterone, growth hormone $(\mathrm{GH})$ and insulin-like growth factor I (IGF-I), as well as the response to suckling and some parameters of mammary gland function. The effects of hypothyroidism during pregnancy and lactation were also compared with its effects on virgin rats that were subjected to 30 or 50 days of propylthiouracyl treatment, corresponding to the approximate duration of treatment at the end of pregnancy and the end of lactation, respectively.

\section{Materials and Methods}

\section{Animals and experimental design}

Adult female Wistar rats bred in the authors' laboratory, aged 3-4 months, weighing 200-230 g at the onset of treatment and with regular 4-day cycles were used. The rats were kept in a light- (lights on from 06:00 h to $20: 00 \mathrm{~h})$ and temperature-controlled $\left(22-24^{\circ} \mathrm{C}\right)$ room.
Rat chow (Cargill, Cordoba) and tap water or propylthiouracyl solution were available ad libitum. Hypothyroidism was induced by administration of propylthiouracyl at a concentration of $0.1 \mathrm{~g} \mathrm{I}^{-1}$ in the drinking water. The treatment was started on the day of oestrus at day 8 before mating. The presence of spermatozoa in the vaginal smears the morning after caging with a fertile male on the night of pro-oestrus was considered indicative of pregnancy and this day was counted as day 0 of pregnancy. At day 2 or 3 before delivery the rats were caged individually. The day and approximate hour of delivery and the size and weight of the litters were recorded. On day 1 of lactation, the number of pups in each litter was standardized to eight.

Blood was collected from the tail vein of propylthiouracyl-treated or control rats $(n=8-10$ per group) under light ether anaesthesia on days 5 (at 19:00 h), 10, 15, 20 (all at 12:00 h) and 21 (18:00 h) of pregnancy, and on days 2, 5, 10, 15 and 20 of lactation (at 16:00 h) to determine the pattern of hormone secretion during pregnancy and lactation. Some groups of rats were killed on day 21 of pregnancy at 18:00 $\mathrm{h}$ or on days 2, 15 and 20 of lactation at 10:00-12:00 h by decapitation for mammary gland studies. The pups from the groups killed on day 20 of lactation were decapitated and trunk blood was collected for measurement of serum hormone concentrations. Additional groups of virgin rats that had received no treatment or that had received 30 or 50 days of propylthiouracyl treatment in the drinking water were killed by decapitation at 09:0010:00 $\mathrm{h}$ on the day of dioestrus for studies of serum hormone concentrations and the mammary glands. These durations of treatment were chosen for the virgin rats to approximate to the duration of the propylthiouracyl treatment received by the parous groups at the end of pregnancy (day 21) and the end of lactation (day 20), respectively. Trunk blood was collected and the serum was separated by centrifugation at $1800 \mathrm{~g}$ for $15 \mathrm{~min}$ and stored at $-30^{\circ} \mathrm{C}$ until used. The inguinal mammary glands from the dams or virgin rats were removed, washed in a cold saline solution and stored at $-70^{\circ} \mathrm{C}$ until they were analysed.

On day 10 or 11 of lactation, control or propylthiouracyl-treated mothers ( $n=16$ per group) were isolated from their litters at 08:00 $\mathrm{h}$ to determine the response to suckling. The litters were weighed and half of the litters from control or hypothyroid rats were reunited with mothers from the other group at 16:00 $h$, whereas the rest of the litters were reunited with their own mothers. After 30 min of vigorous suckling, blood was collected from the tail vein of the mothers under light ether anaesthesia; the litters were weighed again and then returned to their own mothers. Serum was separated and stored at $-30^{\circ} \mathrm{C}$ for prolactin and oxytocin radioimmunoassay.

The experiments were approved by the institutional committee of bioethics. 


\section{Determination of hormone concentrations}

Prolactin, thyroid stimulating hormone (TSH), LH and $\mathrm{GH}$ concentrations were measured by double antibody radioimmunoassay using materials generously provided by A. F. Parlow and the NHPP (National Hormone and Pituitary Program, Harbor-UCLA Medical Center, Torrance, CA). The hormones were radio-iodinated using the Chloramine $\mathrm{T}$ method and purified by passage through Sephadex G75. The results were expressed in terms of the rat prolactin RP-3, TSH RP-3, LH RP-3 or rat GH RP-2 standard preparations. Assay sensitivity was $0.5 \mu \mathrm{g} \mathrm{I}^{-1}$ serum and the inter- and intra-assay coefficients of variation were $<10 \%$ for all hormones.

Oxytocin concentration was measured by double antibody radioimmunoassay using an antibody and purified oxytocin generously provided by N. Hagino and Novartis Argentina, respectively. The hormone was radioiodinated using the Chloramine $\mathrm{T}$ method and purified by passage through Sephadex G50. The standard curve was prepared using the same preparation of purified oxytocin used for radioiodination. Sensitivity of the assay was maximized by incubating the standards and serum samples for $24 \mathrm{~h}$ with appropriate dilution of the antibody; the labelled hormone $\left(8-10 \times 10^{3}\right.$ c.p.m.) was added and the tubes were incubated overnight before addition of the second antibody. Assay sensitivity was $8 \mathrm{ng} \mathrm{I}^{-1}$ serum and the intra-assay coefficient of variation was $<10 \%$. All the samples were measured in the same assay in duplicate.

Serum progesterone concentration was measured using a radioimmunoassay developed in the authors' laboratory (Bussmann and Deis, 1979) with an antiserum raised in rabbits against progesterone-11-BSA conjugate. Assay sensitivity was $<70 \mathrm{fmol}$ per tube and the interand intra-assay coefficients of variation were $<10 \%$.

Rat IGF-I, oestradiol, testosterone, corticosterone, triiodothyronine and tetraiodothyronine concentrations in sera were measured by radioimmunoassay using commercial kits for total hormones (DSL-2900, DSL4800, DSL-4100, DSL-81100, DSL-3100 and DSL-3200 double antibody radioimmunoassay, respectively; all from Diagnostic Systems Laboratories, Webster, TX).

\section{Mammary gland histology}

Mammary tissue was fixed in buffered phormol, dehydrated in ethanol and embedded in paraffin wax. Sections of 3-5 $\mu \mathrm{m}$ thickness were cut with a ReichertJung $\mathrm{Hn} 40$ microtome and stained with haematoxylineosin. Images were taken with a Zeiss Axioscop 2 light microscope fitted with a Sony CCD-IRIS/RGB videocamera under $\times 100$ and $\times 400$ magnifications. Only the inguinal mammary glands were used for all the morphological analyses. Sections were evaluated histologically for changes in the extent of lobuloalveolar development and supporting adipose tissue, and for the extent of ducto-lobular luminal secretions. The morphological state of the alveoli was determined by analysing serial sections from three different animals per group.

\section{Determination of casein and lactose concentrations}

Mammary casein and lactose concentrations were measured as described by Jahn and Deis (1991). In brief, $200 \mathrm{mg}$ samples of mammary tissue were cut into small pieces and homogenized in $2 \mathrm{ml}$ of $50 \mathrm{mmol}$ sodium phosphate buffer $\mathrm{I}^{-1}, 150 \mathrm{mmol} \mathrm{NaCl} \mathrm{I}{ }^{-1}, 0.1 \%$ $(\mathrm{w} / \mathrm{v}) \mathrm{NaN}_{3}$ and $0.1 \%(\mathrm{v} / \mathrm{v})$ Triton-X100, $\mathrm{pH} 7.6$ with an Ultraturrax homogenizer. The homogenate was centrifuged at $600 \mathrm{~g}$ for $30 \mathrm{~min}$ and the supernatant was used for $\beta$-casein determination by a homologous radioimmunoassay according to Edery et al. (1984), as modified in the authors' laboratory by Bussmann and Deis (1985). Lactose concentration was assessed by the method of Kuhn and Lowenstein (1967).

\section{Statistical analysis}

Statistical analysis was performed using Student's $t$ test or ANOVA, followed by the least significant difference between means test when more than two means were compared (Snedecor and Cochran, 1967). Differences between means were considered significant at $P<0.05$.

\section{Results}

Effect of propylthiouracyl treatment on serum triiodothyronine, tetraiodothyronine and TSH concentrations in virgin, pregnant and lactating rats

In control rats, circulating tetraiodothyronine concentrations were higher in virgin rats than at the beginning of pregnancy; tetraiodothyronine concentrations continued to decrease during pregnancy, reaching a nadir before delivery. There was a sharp increase in tetraiodothyronine concentrations after parturition, in accordance with previous results (Galton, 1968; Fukuda et al., 1980; Calvo et al., 1990; Rosato et al., 2002). In the propylthiouracyl-treated rats there was also an increase in tetraiodothyronine concentrations after parturition, which was clearly attenuated compared with the control rats. Serum triiodothyronine concentrations were lower in pregnant than in virgin rats, and remained roughly constant during pregnancy and lactation, with the exception of marked increases on day 20 of pregnancy and day 2 of lactation (Fig. 1). To our knowledge, these peaks of secretion before and after delivery have not been described by other authors. The propylthiouracyltreated rats had very low circulating tetraiodothyronine concentrations and the changes observed in the control rats were not observed (Fig. 1). The propylthiouracyltreated rats also had significantly reduced serum 

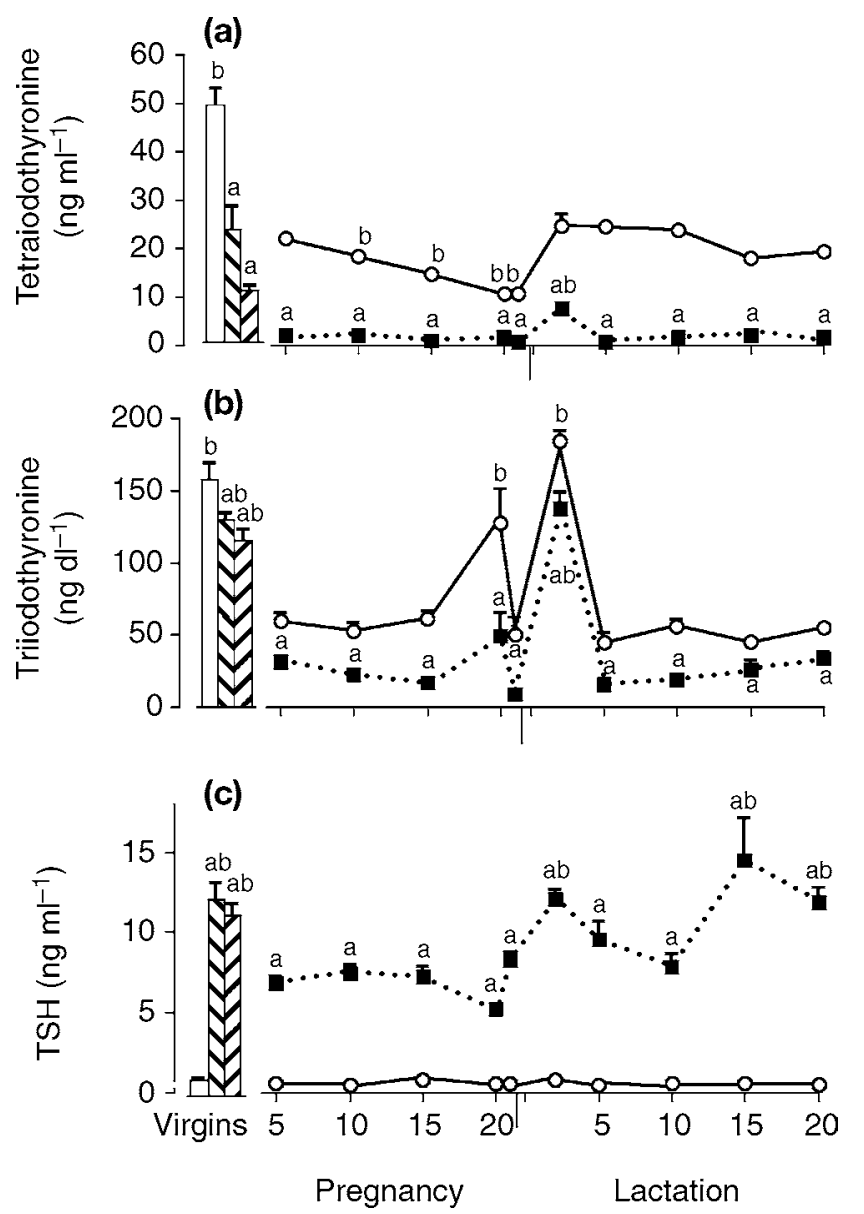

Fig. 1. Circulating (a) tetraiodothyronine, (b) triiodothyronine and (c) TSH concentrations during pregnancy and lactation in control (O) and hypothyroid (propylthiouracyl-treated; $\mathbf{0})$ rats, and in control virgin rats $(\square)$ or virgin rats treated for $30(\mathbb{\nabla})$ or $50(\square)$ days with propylthiouracyl. Propylthiouracyl was administered in the drinking water at a concentration of $0.1 \mathrm{~g} \mathrm{I}^{-1}$. The results represent the mean \pm SEM ( $n=8-12$ rats per group). ${ }^{\text {a }} P<0.05$ compared with respective control group. ${ }^{b} P<0.05$ compared with respective value on day 5 of pregnancy.

triiodothyronine concentrations, although the decrease was relatively small compared with the decrease in tetraiodothyronine concentrations, and the peaks before and after delivery were still present, although attenuated (Fig. 1). In accordance with the hypothyroid state, TSH concentrations were increased more than tenfold in the propylthiouracyl-treated rats (Fig. 1). Although the euthyroid rats did not show significant variations in circulating TSH during pregnancy and lactation, the propylthiouracyl-treated rats had significantly lower $\mathrm{TSH}$ values during pregnancy compared with virgin or lactating rats (Fig. 1). At day 20 of age, the pups were also hypothyroid, with decreased concentrations of tetraiodothyronine $\left(0.5 \pm 0.3 \mathrm{ng} \mathrm{ml}^{-1} ; \quad P<0.001\right)$ and triiodothyronine $\left(98 \pm 17 \mathrm{ng} \mathrm{dl}^{-1} ; P<0.001\right)$, and increased TSH concentrations $\left(4.89 \pm 1.49 \mathrm{ng} \mathrm{ml}^{-1}\right.$;
$P<0.05)$ compared with the concentrations in the control litters (tetraiodothyronine: $27.9 \pm 1.1 \mathrm{ng} \mathrm{m}^{-1}$; triiodothyronine: $216 \pm 40 \mathrm{ng} \mathrm{dl}^{-1}$; TSH: $0.95 \pm 0.20 \mathrm{ng}$ $\mathrm{ml}^{-1}$ ). The passage of propylthiouracyl to the milk may be responsible in part for the hypothyroid state of the litters, although they may also have drunk some of the propylthiouracyl solution available to the mothers and thus become overtly hypothyroid at a late stage of lactation.

\section{Effect of propylthiouracyl treatment on pregnancy, parturition, pup mortality and weight increase on mothers and pups, and weight increase in virgin rats}

Propylthiouracyl treatment for 8 days did not affect the pregnancy rate when the rats were mated on the second pro-oestrus after the start of the treatment. All the rats that showed positive spermatozoa became pregnant and delivered at term, although the duration of gestation was significantly longer $(22.7 \pm 0.2$ days; $P<0.01)$ in the propylthiouracyl-treated rats compared with the control rats (21.8 \pm 0.1 days). Some propylthiouracyltreated rats even gave birth to live litters on days 23 or 24 of pregnancy. The propylthiouracyl-treated rats gave birth to $9.0 \pm 0.5$ pups per litter, which was significantly lower than the mean litter size of the control rats $(12.7 \pm 0.4 ; P<0.01)$. The pups from hypothyroid mothers were significantly lighter at birth $(5.20 \pm 0.11 \mathrm{~g}$; $P<0.001)$ than the control pups $(6.13 \pm 0.12 \mathrm{~g})$. Maternal weight was also significantly lower in the propylthiouracyl-treated rats on day 21 of pregnancy and this difference persisted during lactation (Fig. 2). Virgin rats stopped growing after initiation of propylthiouracyl treatment, whereas control rats increased in weight; at day 50 the difference in weight was significant (inset in Fig. 2). Growth of the litters was severely impaired and pup mortality increased during lactation in the propylthiouracyl-treated group (Fig. 2).

\section{Effect of propylthiouracyl treatment on circulating hormone concentrations in virgin rats}

Propylthiouracyl treatment had marked effects on hormone patterns in the virgin rats. In addition, the virgin rats showed prolonged periods of dioestrous vaginal smears that commenced subsequent to the second cycle after the beginning of propylthiouracyl treatment. Although serum prolactin and progesterone concentrations, measured at 09:00-10:00 $\mathrm{h}$, at days 30 and 50 after the start of propylthiouracyl treatment were similar to controls (Fig. 3), the progesterone values were about $30 \mathrm{ng} \mathrm{m}^{-1}$, which is typical of early dioestrous or pseudopregnancy values, namely of a luteal phase. This finding, associated with the dioestrous vaginal smears, is indicative of pseudopregnancy. Serum prolactin concentrations were measured on the afternoon of day 30 in additional groups of control and propylthiouracyl-treated rats that showed 

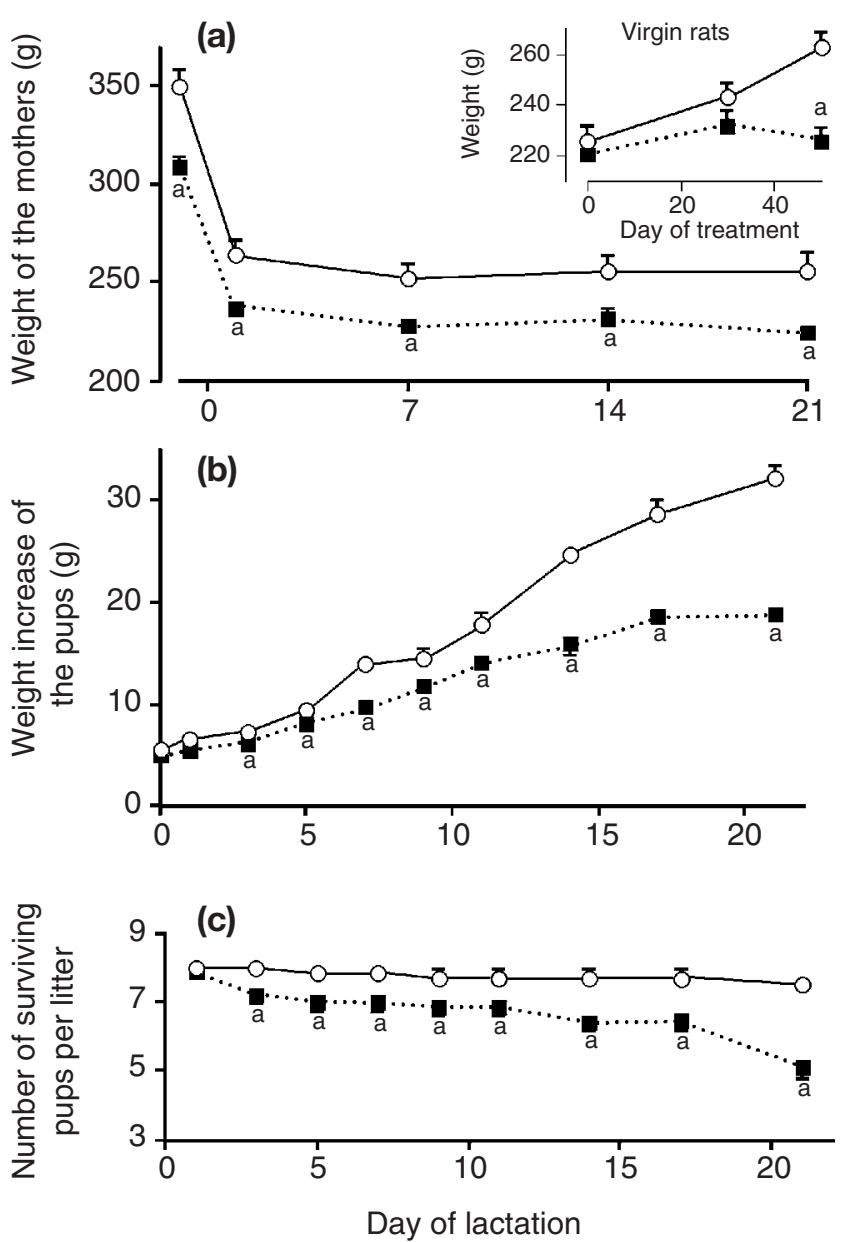

Fig. 2. Growth curves of the (a) mothers and (b) pups, and (c) pup mortality during lactation in control $(\bigcirc)$ and hypothyroid (propylthiouracyl-treated; 口) rats. Inset in (a) shows the growth curve in control and propylthiouracyl-treated virgin rats at 0,30 and 50 days after start of propylthiouracyl treatment. Propylthiouracyl was administered in the drinking water at a concentration of $0.1 \mathrm{~g} \mathrm{I}^{-1}$. Litters were adjusted to eight pups per litter after delivery. The results represent the mean \pm SEM of groups of $8-12$ rats or litters. ${ }^{\text {a }} P<0.05$ compared with respective control group.

a dioestrous smear to confirm the pseudopregnant state. Control rats had prolactin concentrations of $18.1 \pm$ $4.6 \mathrm{ng} \mathrm{ml}^{-1}$, whereas the prolactin concentrations of the hypothyroid rats were $64.2 \pm 15.7 \quad(P<0.01)$, which corresponded to the afternoon peak typical of pseudopregnancy (Freeman, 1994; Carón and Deis, 1997). The virgin rats had decreased circulating concentrations of corticosterone (Fig. 3), GH and IGF-I (Fig. 4) at days 30 and 50 of propylthiouracyl treatment. The virgin rats also had significantly reduced serum $\mathrm{LH}$, but not $\mathrm{FSH}$, concentrations at day 50 of treatment. Circulating testosterone concentration was decreased on both days, whereas oestradiol concentration was decreased at day 50 of treatment only (Fig. 5). These results are indicative of impaired function of the hypothalamo-pituitary-ovarian axis.
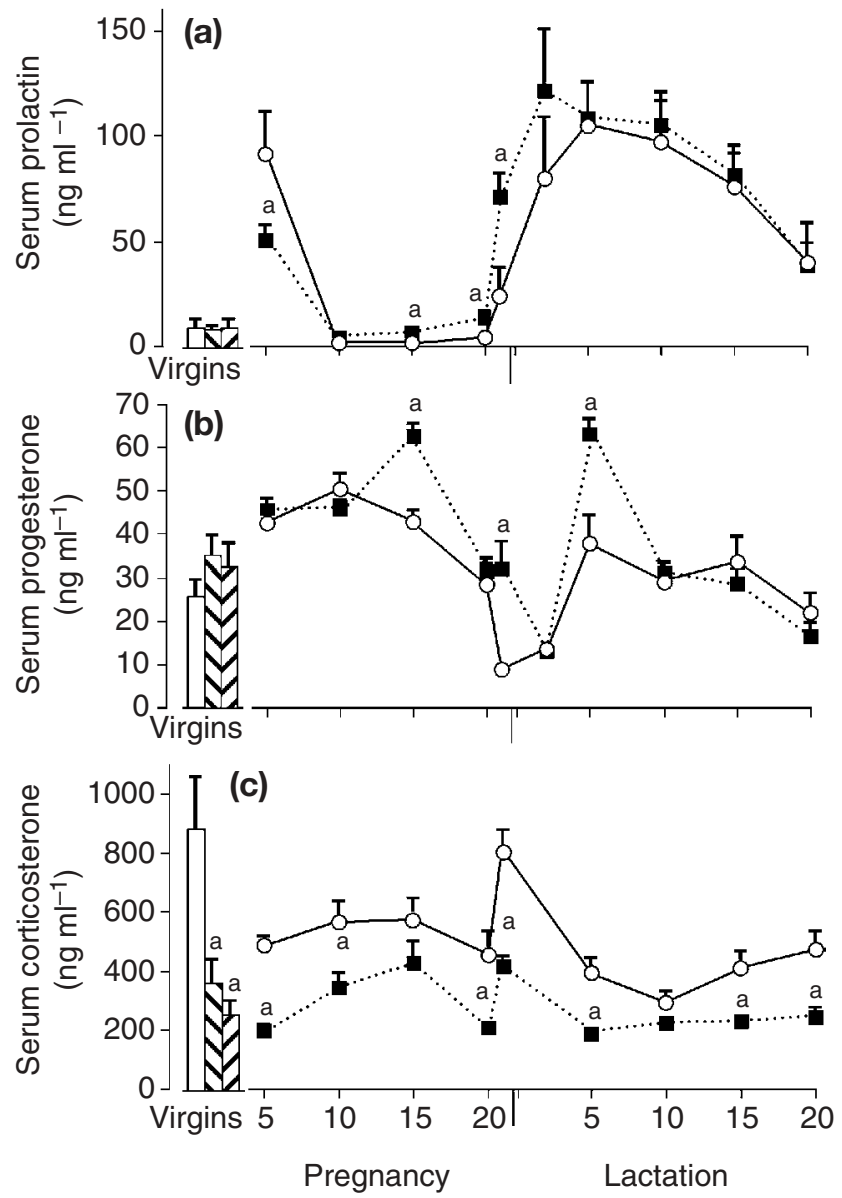

Fig. 3. Circulating (a) prolactin, (b) progesterone and (c) corticosterone concentrations during pregnancy and lactation in control $(\bigcirc)$ and hypothyroid (propylthiouracyl-treated; $\mathbf{\square})$ rats and in control virgin rats $(\square)$ or virgin rats treated for $30(\mathbb{\nabla})$ or 50 ( $\square$ ) days with propylthiouracyl. Propylthiouracyl was administered in the drinking water at a concentration of $0.1 \mathrm{~g} \mathrm{I}^{-1}$. The results represent the mean \pm SEM $\left(n=8-12\right.$ rats). ${ }^{\text {a }} P<0.05$ compared with respective control group.

\section{Effect of propylthiouracyl treatment on circulating hormone concentrations in pregnant and lactating rats}

During pregnancy, the afternoon peak of prolactin concentration on day 5 was attenuated but the basal values of prolactin on days 15, 20 and 21 of pregnancy were increased (Fig. 3). In contrast, the increased concentrations of circulating prolactin produced by the suckling stimulus on the different days of lactation were not affected by the propylthiouracyl treatment (Fig. 3). In accordance with the increased prolactin concentrations on days 15-21 of pregnancy, circulating concentrations of progesterone were also increased on days 15 and 21 of pregnancy, and on day 5 of lactation (Fig. 3). In contrast to these effects, circulating corticosterone concentration was decreased on almost all of the days studied (Fig. 3). In the control rats, serum corticosterone concentration 

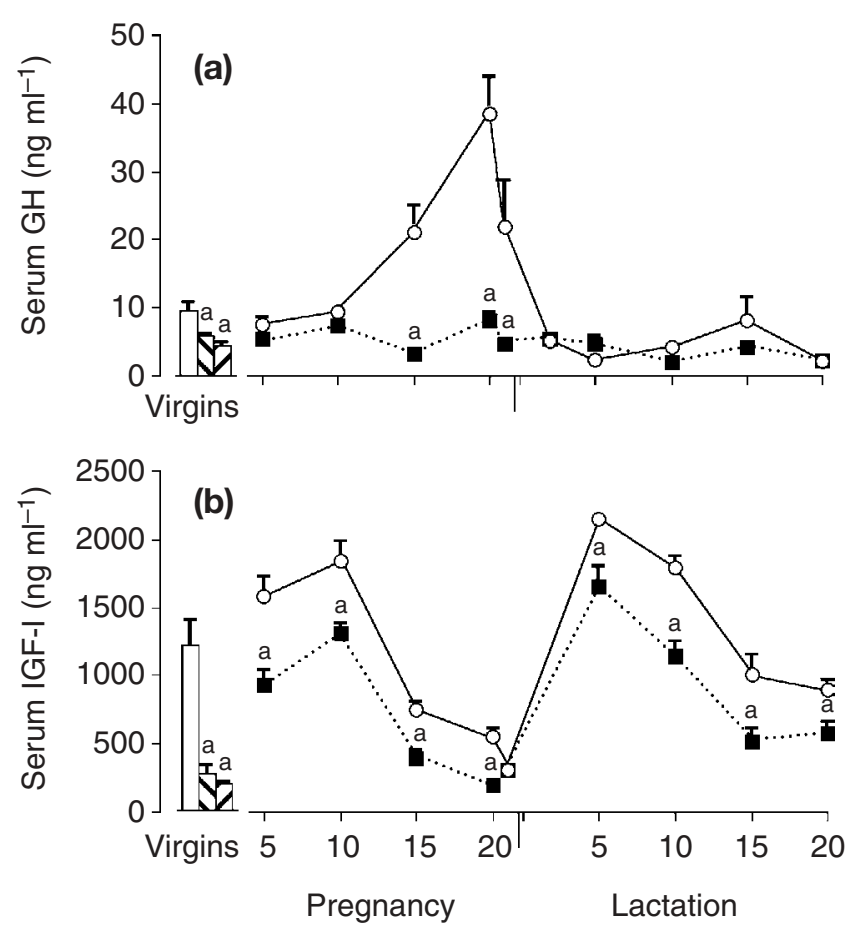

Fig. 4. Circulating (a) growth hormone $(\mathrm{GH})$ and (b) insulinlike growth factor I (IGF-I) concentrations in virgin rats and during pregnancy and lactation in control $(O)$ and hypothyroid (propylthiouracyl-treated; $\mathbf{\square}$ ) rats and in control virgin rats $(\square)$ or virgin rats treated for $30(\mathbb{\nabla})$ or $50(\square)$ days with propylthiouracyl. Propylthiouracyl was administered in the drinking water at a concentration of $0.1 \mathrm{~g} \mathrm{I}^{-1}$. The results represent the mean \pm SEM ( $n=8-12$ rats). ${ }^{\text {a }} P<0.05$ compared with respective control group.

reached a peak value on day 21 of pregnancy, followed by a decrease after parturition. This pattern, although attenuated, was also observed in the propylthiouracyltreated rats. Serum oestradiol concentration, measured on days 20 and 21 of pregnancy, when the concentrations are increasing towards the pre- and post-partum peaks, and on day 2 after parturition, was also significantly decreased in the propylthiouracyl-treated rats (Fig. 5).

The increase in circulating $\mathrm{GH}$ concentration observed on the last 6 days of pregnancy (Jahn et al., 1993) was severely attenuated in the propylthiouracyltreated rats, whereas after parturition, $\mathrm{GH}$ values were very low and similar in both groups of rats (Fig. 4). As described by Rosato et al. (2002), circulating IGF-I concentration decreased during pregnancy to minimal values on day 21 , showed a marked increase during early lactation and decreased slowly thereafter. Circulating IGF-I concentrations were also decreased in the propylthiouracyl-treated rats on all days of pregnancy and lactation, with the exception of day 21 of pregnancy, when the lowest values were observed in both groups of rats (Fig. 4).
Effect of propylthiouracyl treatment on mammary development and function

The stunted growth of the litters in the propylthiouracyl-treated rats, as well as the differences in circulating concentrations of hormones that are relevant to mammary development and function, in particular the decreases in GH and IGF-I during pregnancy and the persistence of increased progesterone concentration, may be indicative of an impairment in mammary function or in the suckling-induced milk ejection reflex, despite the normal or increased (on late pregnancy) concentrations of prolactin, the main lactogenic hormone. In the present study, casein and lactose contents of the mammary glands were determined as an estimation of the milk-producing capacity of the glands. On day 21 of pregnancy the propylthiouracyl-treated rats had significantly increased mammary casein content compared with the controls, whereas there were no differences in lactose content on that day or on casein and lactose content during lactation (Fig. 6). As expected, both milk components were higher in the lactating rats compared with the concentrations in late pregnancy in both control and propylthiouracyl-treated rats.

Histological analysis of haematoxylin-eosin preparations of mammary tissue (Fig. 7) showed that the virgin rats had an extent of mammary development similar to that observed at early or midpregnancy, and that some of the preparations showed signs of active secretion, whereas others did not. Control virgin rats showed the predominantly ductal development typical of the nonpregnant state. In accordance with this observation, mammary casein content was very low in the control virgin rats, whereas the propylthiouracyl-treated rats had variable casein values, ranging from very low to those indicative of active milk synthesis ( $>7 \mu \mathrm{g}(\mathrm{mg} \text { tissue })^{-1}$; Fig. 6). In contrast, histological analysis of mammary tissue from rats on day 21 of pregnancy or on days 2 and 20 after parturition showed no differences between the control and propylthiouracyl-treated rats (data not shown). This finding, together with mammary casein and lactose values, as well as prolactin secretion after parturition, is indicative of normal lactogenesis and active milk synthesis by mammary glands during late pregnancy and lactation.

Effect of propylthiouracyl treatment on suckling-induced hormone release and milk ejection

An acute suckling experiment was performed in control and propylthiouracyl-treated rats at mid-lactation (days 10-11 after parturition) to investigate the milk ejection reflex induced by suckling; the experiment consisted of measuring serum prolactin and oxytocin concentrations, as well as the amount of milk ingested by the litter (measured by the increase in weight), after 
(a)

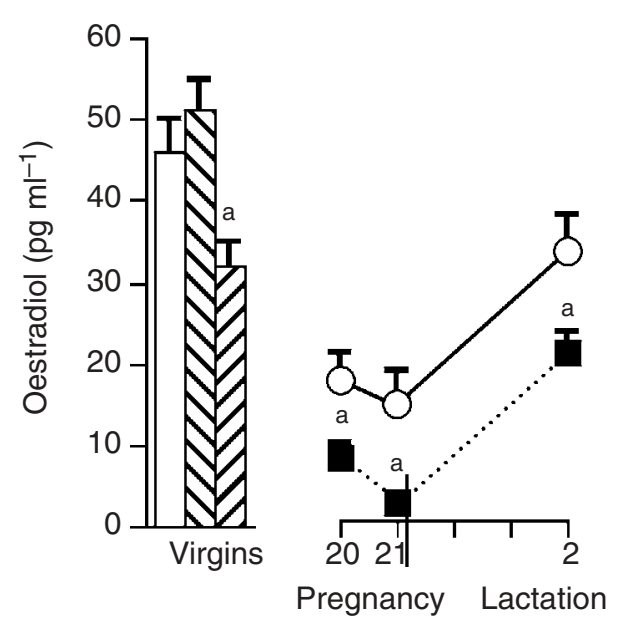

(b)

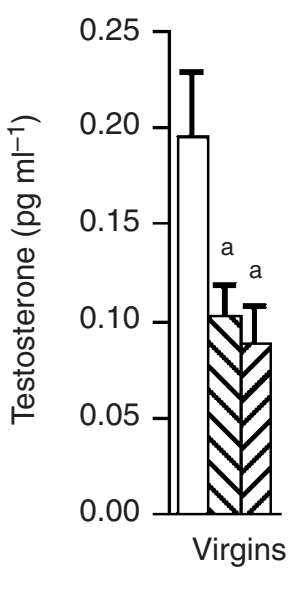

(c)

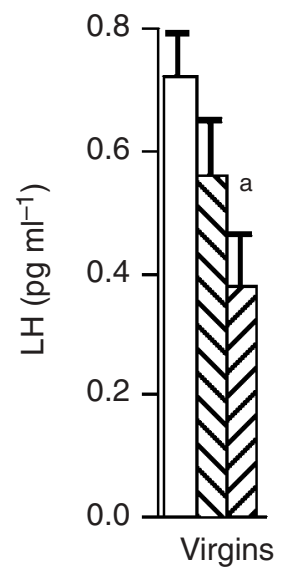

(d)

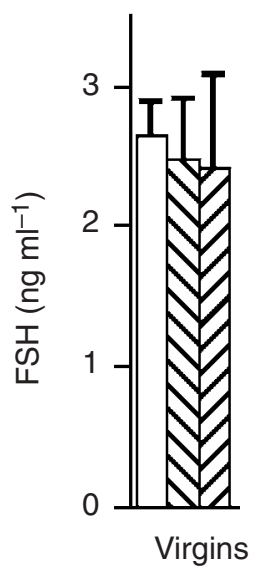

Fig. 5. Circulating (a) oestradiol, (b) testosterone, (c) LH and (d) FSH concentrations in control virgin rats ( $\square$ ), and hypothyroid virgin

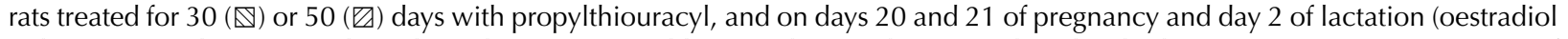
only; $\bigcirc$ : control group; $\mathbf{a}$ : hypothyroid group). Propylthiouracyl was administered in the drinking water at a concentration of $0.1 \mathrm{~g} \mathrm{I}^{-1}$. The results represent the mean $\pm \operatorname{SEM}(n=8-12$ rats). a $P<0.05$ compared with respective control group.

30 min suckling by a litter of eight pups to mothers that had been separated from the litter for $8 \mathrm{~h}$. As the difference in growth of the control and propylthiouracyltreated pups indicates that the propylthiouracyl-treated pups may be significantly weaker than the controls, the experiment was performed on four groups of animals: propylthiouracyl-treated and control mothers suckled by their own litters; control mothers suckled by pups from the propylthiouracyl-treated group; and propylthiouracyl-treated mothers suckled by control pups. There were no differences in the suckling-induced release of prolactin, but the propylthiouracyl-treated mothers released less milk than did the control mothers, regardless of whether they were suckled by their own or control litters (Fig. 8). The pups of propylthiouracyltreated mothers may have been weakened too, as they obtained less milk from both groups of mothers. In accordance with their reduced capacity to eject milk, the propylthiouracyl-treated mothers had significantly lower circulating oxytocin concentrations after suckling compared with control mothers (Fig. 8).

\section{Discussion}

The results of the present study demonstrate that the hypothyroidism induced by propylthiouracyl treatment had significant effects on virgin rats and on pregnancy and lactation, as evidenced by alterations in the hormone patterns, as well as by the profound impact on litter growth. Some part of this impairment in litter growth is the result of the hypothyroid state of the pups produced by passage of propylthiouracyl to the milk, but impairments in the milk ejection reflex were also found, indicating a compromised ability of the mothers to release milk despite the normal release of prolactin. Although propylthiouracyl is excreted poorly into milk, at least in humans, milk concentrations achieve onetenth of serum concentrations (Kampmann and Hansen, 1981; Momotani et al., 2000), which may have induced a mild hypothyroid state in the pups and contributed to their retarded growth and development. Thus, the growth impairment may be a consequence of undernourishment due to inadequate milk supply, together with a mild state of hypothyroidism due to the passage of propylthiouracyl to milk, even in low amounts. After the pups have opened their eyes, at about day 15 of life, they are also able to drink the water or propylthiouracyl solution available to the mothers, and may have become even more hypothyroid. Nevertheless, the growth retardation was observed from birth and is clearly not due to any ingestion of propylthiouracyl solution by the pups.

The pattern of serum tetraiodothyronine values showed a decrease during pregnancy and an increase after parturition, which is a consequence of the increased rates of plasma clearance for triiodothyronine and tetraiodothyronine (Versloot et al., 1994). This increased clearance is a result of increased metabolism and excretion of free iodide from thyroid hormones in the liver and other peripheral tissues (Galton, 1968; Fukuda et al., 1980; Calvo et al., 1990). The propylthiouracyltreated rats also showed an attenuated increase in tetraiodothyronine concentration after delivery. Two peaks in serum triiodothyronine concentration were observed in the control and propylthiouracyl-treated rats, on day 20 of pregnancy and day 2 of lactation. The second peak may correspond to the parallel increase in 
(a)

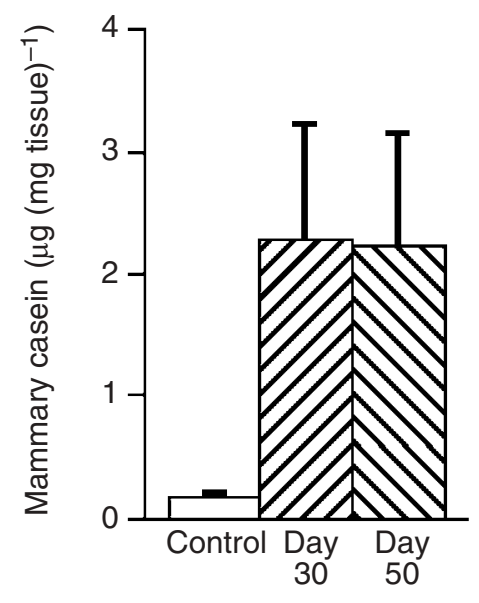

(c)

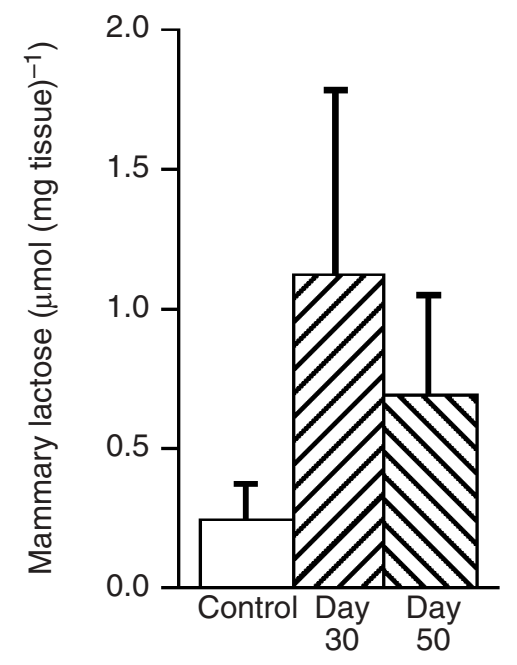

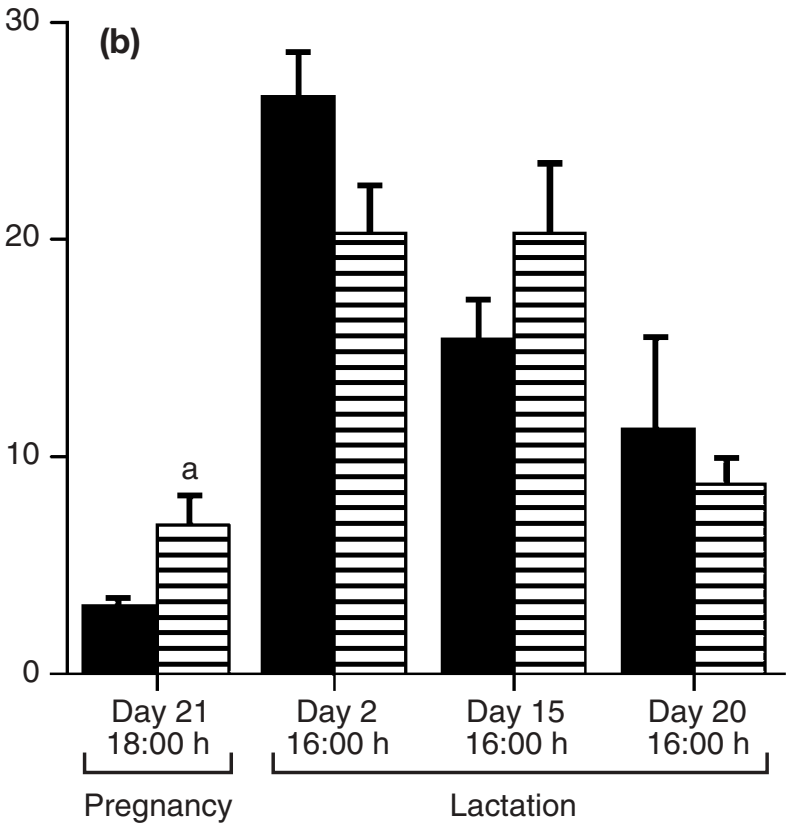

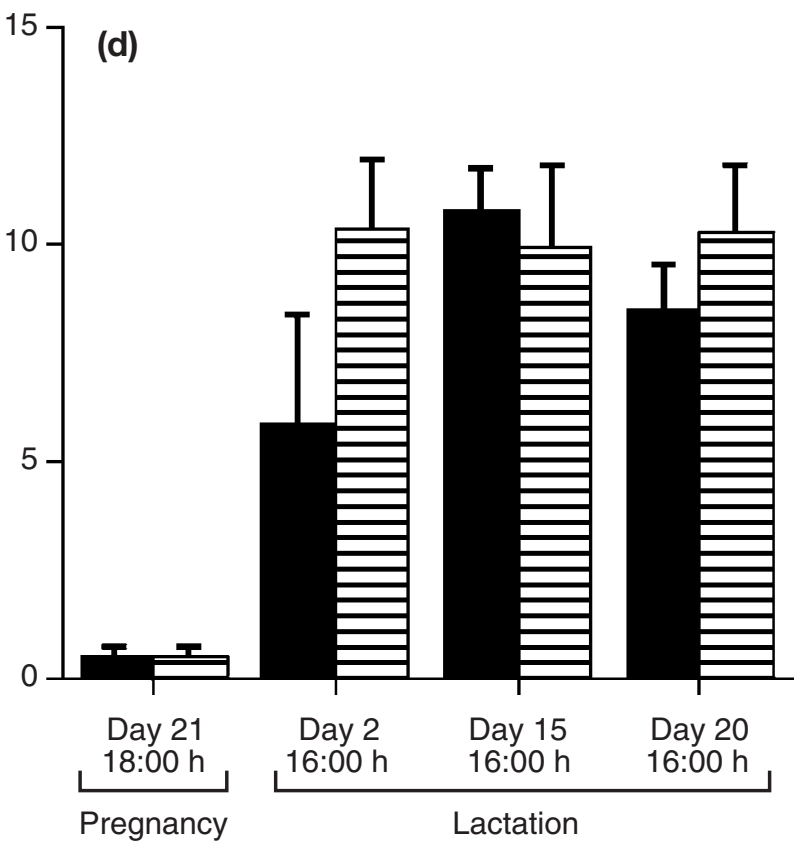

Fig. 6. Mammary concentrations of $(a, b)$ casein and $(c, d)$ lactose in $(a, c)$ virgin rats that had received vehicle

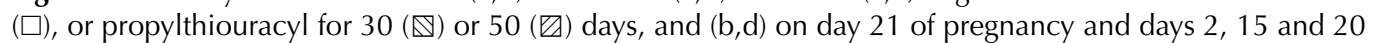
of lactation in control ( $\mathbf{\square})$ and hypothyroid (propylthiouracyl-treated; $巨)$. Propylthiouracyl was administered in the drinking water at a concentration of $0.1 \mathrm{~g} \mathrm{I}^{-1}$. The results represent the mean $\pm \operatorname{SEM}(n=8-12$ rats). ${ }^{a} P<0.05$ compared with respective control group.

tetraiodothyronine concentration after delivery (Fukuda et al., 1980), but no such correlation was found for the peak in late pregnancy. It is possible that the increase in deiodinases during late pregnancy may have produced this transitory increase in serum triiodothyronine concentration.
In virgin rats, decreases in circulating corticosterone, GH and IGF-I concentration were observed, as were prolonged periods of dioestrus that corresponded to pseudopregnancies, as demonstrated by increased concentrations of progesterone and afternoon prolactin serum concentrations, compatible with a luteal phase. 

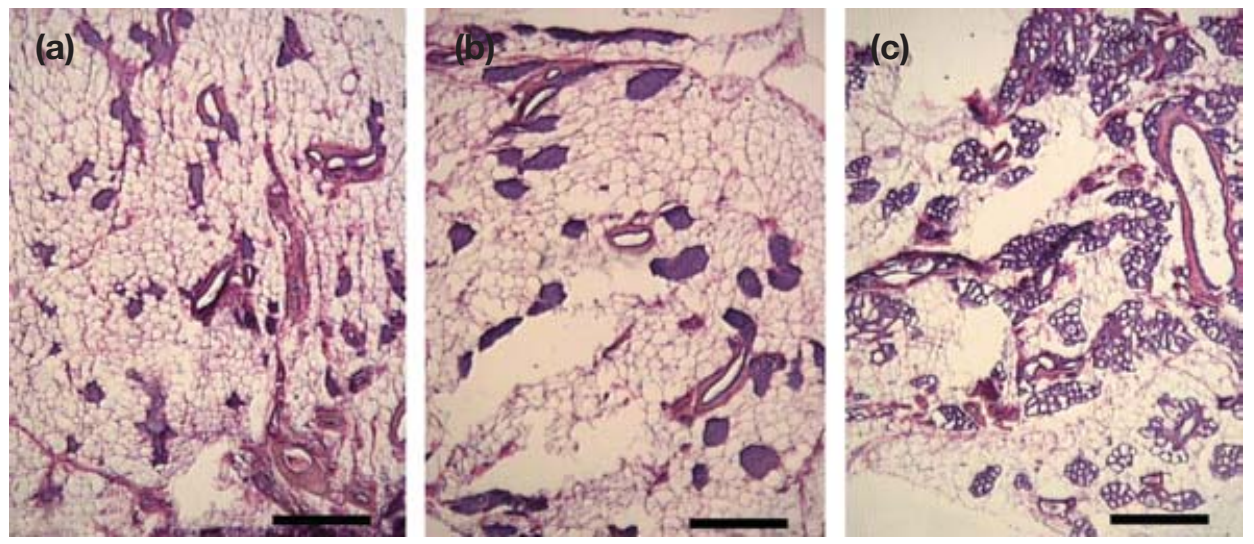

Fig. 7. Histology of mammary glands from (a) control and $(b, c)$ hypothyroid virgin rats. Mammary glands from rats treated for 30 or 50 days with propylthiouracyl $\left(0.1 \mathrm{~g} \mathrm{I}^{-1}\right)$ in the drinking water were fixed and stained with haematoxylin-eosin. (a) Control rats show mainly ductal development, whereas hypothyroid rats show moderate lobulo-alveolar development, (c) with or (b) without signs of active secretion (distended alveoli). The images were similar at days 30 or 50 of treatment. The images were obtained at x 100 magnification. Scale bars represent $100 \mu \mathrm{m}$.

(a)

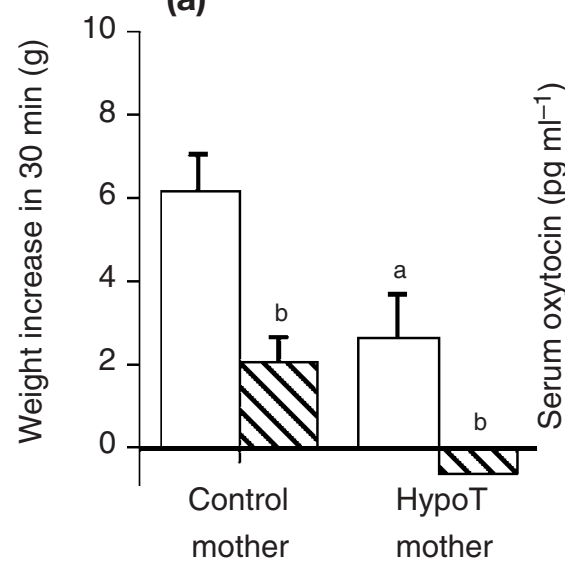

(b)

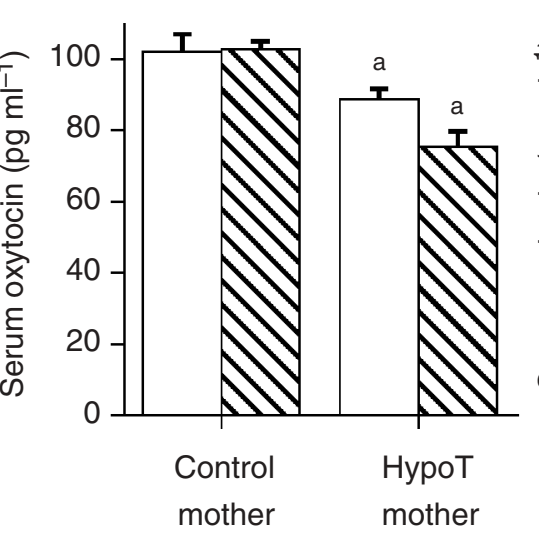

(c)

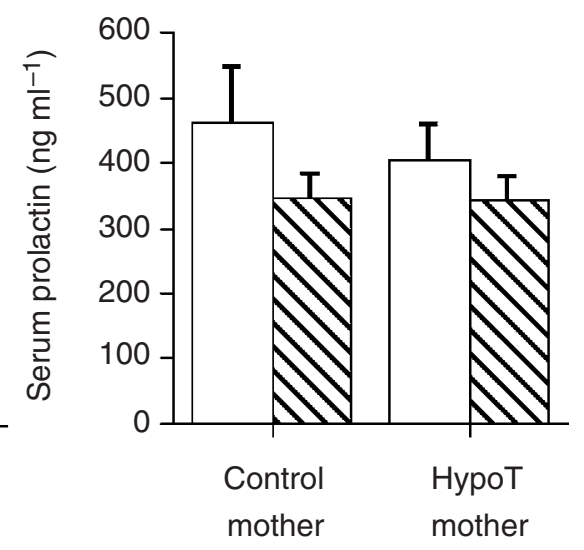

Fig. 8. Effect of 30 min suckling after $8 \mathrm{~h}$ separation on (a) milk ejection, estimated by the change in litter weight after the 30 min suckling period, and serum (b) oxytocin and (c) prolactin concentrations at mid-lactation (days 10-11 after parturition) in control or hypothyroid (HypoT) mothers suckled by control pups $(\square)$ or hypothyroid pups $(\mathbb{\nabla})$. The litters were separated from their mother for $8 \mathrm{~h}(\mathrm{at}$ 08:00 h) and reunited for $30 \mathrm{~min}$ (from 16:00 h to 16:30 h). The litters were weighed before and after the 30 min suckling period, and blood samples were collected from the mothers for radioimmunoassay. The results represent the mean \pm SEM ( $n=8-12$ rats per group). ${ }^{\text {a }} P<0.05$ compared with respective control group. ${ }^{b} P<0.05$ for hypothyroid pups compared with control pups.

These results confirm those of Mattheij et al. (1995), who also deduced, on the basis of the increased serum progesterone concentrations, that hypothyroidism induced pseudopregnancies in female rats. This pseudopregnant state was capable of inducing a degree of mammary development, with signs of milk production in some rats, despite the decreased circulating corticosterone, oestradiol, GH and IGF-I concentrations, all of which are mitogenic factors that contribute to mammary alveolar proliferation and differentiation. The decreases in circulating $\mathrm{LH}$, oestradiol and testosterone concentrations in the virgin rats may indicate a slight but progressive impairment in hypophyseal (gonadotrophic) and ovarian steroidogenic function, which, nevertheless, is compatible with the maintenance of pseudopregnancy.

There were important differences in the serum concentrations of prolactin, GH, IGF-I, corticosterone, oestradiol and progesterone during pregnancy, all of which are hormones that are important for mammary development (Topper and Freeman, 1980). Although the increases in prolactin and progesterone concentration may have favoured mammary lobulo-alveolar growth, the decreases in the other four hormones may have opposed this effect. Overall, mammary histology showed no gross effect of propylthiouracyl treament on mammary lobulo-alveolar development in late pregnancy and 
lactation. The decrease in circulating progesterone concentration is known to serve as the trigger for the initiation of milk synthesis during late pregnancy (Deis, 1968; Vermouth and Deis, 1972; Deis et al., 1989). The increase in mammary casein content observed on day 21 in the propylthiouracyl-treated rats is indicative of normal lactogenesis, despite the increased concentrations of progesterone, which is inhibitory to the lactogenic process. Fujimoto et al. (1996) showed that propylthiouracyl treatment reduces oestrogen induction of progesterone receptor through a reduction in expression of oestrogen receptors in pituitary tumours. A similar mechanism in mammary tissue may have prevented the inhibitory effects of the increased progesterone concentration at the end of pregnancy and thus may account for the increased casein content. Mammary casein and lactose contents in the lactating rats were not modified by propylthiouracyl treatment, which is indicative of normal milk synthesis despite reduced circulating thyroid hormone concentrations. These hormones are important for the synthesis of milk components (Vonderhaar, 1979) and are necessary mediators in the stimulatory actions of prolactin and $\mathrm{GH}$ on milk synthesis in lactating mice (Capuco et al., 1999). It is possible that the decrease in circulating thyroid hormones in the propylthiouracyltreated lactating mothers was not sufficient to inhibit milk synthesis in the presence of normal concentrations of prolactin and $\mathrm{GH}$.

It is not possible to exclude other defects in mammary function produced by the alterations in hormonal patterns, such as defective responses to oxytocin caused by the altered pattern of ovarian hormone secretion. In accordance with this idea, in the acute suckling experiment, propylthiouracyl-treated mothers had a reduced ability to excrete milk by suckling and a slight but significant reduction in oxytocin secretion. The latter may be partially responsible for the impaired response to suckling. The oxytocin deficit may have caused a degree of milk stasis, which is known to impair mammary function and to induce premature regression of the gland (Li et al., 1997; Marti et al., 1999; Varas et al., 2002). The deficits in circulating IGF-I, GH and corticosterone concentrations do not appear to have produced gross changes in mammary function during lactation, or may have been compensated for by the normal quantities of prolactin.

The propylthiouracyl-treated rats also showed delayed parturition and a reduced number of pups, thereby confirming results obtained by Parrot et al. (1960). The delay in the decrease in circulating progesterone concentration, together with the decreased oestradiol concentrations, may have been responsible for the delay in parturition. It is interesting to note that hyperthyroid pregnant rats show premature delivery caused by premature luteolysis, which advances the timing of the decrease in serum progesterone concentration (Rosato et al., 1992, 1998). Hyperthyroid rats also deliver more pups (Rosato et al., 1992) as a result of an increase in ovulation rate (Jahn et al., 1995), and have absence of lactation and impaired maternal behaviour (Rosato et al., 1992). Thus, some of the effects of hypothyoidism are opposite to those of hyperthyroidism and appear to be secondary to the primary effects on ovarian function and the release of pituitary hormones. In contrast, $\mathrm{GH}$ release at the end of pregnancy (Rosato et al., 1998) and the suckling-induced hormone release in lactating rats (Varas et al., 2002) were decreased by both hyperthyroidism and by hypothyroism (present study), although probably through different mechanisms.

Jahn et al. (1993) described an opposite regulation of prolactin and $\mathrm{GH}$ during the end of pregnancy. Thus, the premature increase in prolactin concentration and the decreased concentrations of $\mathrm{GH}$ during late pregnancy in the hypothyroid rats may be related. However, it is also possible that the hypothyroid state may have stimulated the hypothalamic release of TRH, which is a potent releaser of prolactin, and that this TRH may be responsible for the increased prolactin concentration at the end of pregnancy (Mueller et al., 1973; Deis and Alonso, 1975; Bridges et al., 1983). Furthermore, it has been reported that TRH participates in the suckling-induced release of prolactin during lactation (Blake, 1974; de Greef et al., 1987). In the same sense, thyroid hormones are necessary for normal $\mathrm{GH}$ secretion (Burstein et al., 1979; Hendrich and Porterfield, 1992) and the hypothyroid state may have directly prevented the increase in $\mathrm{GH}$ concentration observed during late pregnancy (Hendrich and Porterfield, 1992). It is also possible that the regulation of prolactin secretion may be more complicated, as the attenuation of the afternoon peak on day 5 of pregnancy may be indicative of an impairment in the neuroendocrine reflex that triggers and maintains the semicircadian prolactin rhythm characteristic of the first half of pregnancy in rats (Freeman, 1994).

There are contradictory results on the effect of thyroid hormone excess or deficit on mammary tumorogenesis (Smyth, 1997; Sarlis et al., 2002). Administration of propylthiouracyl or tetraiodothyronine to rats treated with different mammary carcinogens can, depending on the experimental model, result in increased or decreased growth of mammary tumours, although most reports indicate that hypothyroidism reduces tumour growth or decreases their incidence (Vorherr, 1978; Al-Jurf et al., 1982; Vonderhaar and Greco, 1982; Rose and Mountjoy, 1983). Thyroid hormones also modulate the expression of various mammary proteins involved in cellular proliferation and invasive capacities (Vonderhaar et al., 1986; De Lanuoit and Kiss, 1989; Sumitani et al., 1991; Gonzalez-Sancho et al., 1999). In the present study, mammary development was observed in the propylthiouracyl-treated virgin rats, together with decreases in circulating IGF-I and corticosterone concentrations, factors that contribute to mammary mitogenesis. 
Rosato et al. (1998, 2002) demonstrated that chronic tetraiodothyronine administration had opposite effects, decreasing corticosterone concentration with no changes in IGF-I concentration. The divergent effects of thyroid hormone manipulations on mammary carcinogenesis could be caused by the timing of the interactions between the metabolic effects of thyroid hormone excess or deficit, together with the described hormonal changes that will affect mammary proliferation.

The results of the present study demonstrate that hypothyroidism produces various alterations in the hormonal profiles of virgin and pregnant rats, inducing mammary development in virgin rats and having a subtle impact on mammary function during lactation. The inhibition of the milk ejection reflex may account in part for the reduced growth rate of the litters. The effects on mammary development and function, as well as in hormone profiles, may also have relevance in the determination of mammary susceptibility to carcinogenesis.

This work has been supported by grants PIP 0826 from CONICET (National Investigation Council of Science and Technology, Argentina), PMT-PICT 01930 and PMT-PICT 06877 from the Agencia de Promoción Científica y Tecnológica, Argentina. The authors are indebted to R. P. Deis, R. Caron and M. Soaje for critical reading of the manuscript. G. A. Jahn is Career Scientist from CONICET, M. B. Hapon has fellowships from CONICET and PROGRESAR-PLACIRH, and $M$. Simoncini is an undergraduate student of Medical Sciences at the Universidad Nacional de Cuyo, Argentina and had a Student Research Fellowship from the Medical Sciences School of UNCuyo.

\section{References}

Aceves C and Valverde C (1989) Type I, 5'-monodeiodinase activity in the lactating mammary gland Endocrinology 124 2818-2820

Al-Jurf AS, Suleiman SA and Erenberg AP (1982) Effect of altered thyroid status on lysosomal enzymes and thymidylate synthetase activity in tumors and livers of host animals Journal of Surgical Oncology 20 21-24

Becks GP and Burrow GN (1991) Thyroid disease and pregnancy Medical Clinics of North America 75 121-150

Blake CA (1974) Stimulation of pituitary prolactin and TSH release in lactating and proestrous rats Endocrinology 94 503-508

Bridges RS, Terkel J and Sawyer CH (1983) Thyroid stimulating hormone and prolactin secretion: reduced sensitivity to TRH-stimulated prolactin release after midpregnancy in rats Proceedings of the Society of Experimental Biology and Medicine 173 527-532

Burstein PJ, Draznin B, Johnson CJ and Schalch DS (1979) The effect of hypothyroidism on growth, serum growth hormone, the growth hormone-dependent somatomedin, insulin-like growth factor, and its carrier protein in rats Endocrinology 104 1107-1111

Bussmann LE and Deis RP (1979) Studies concerning the hormonal induction of lactogenesis by prostaglandin $\mathrm{F}_{2 \alpha}$ in pregnant rats Journal of Steroid Biochemistry 11 1485-1489

Bussmann LE and Deis RP (1985) Hormonal regulation of casein synthesis at the end of pregnancy Molecular and Cellular Endocrinology 37 115-118

Calvo R, Obregon MJ, Ruiz de Ona C, Ferreiro B, Escobar Del Rey E and Morreale de Escobar G (1990) Thyroid hormone economy in pregnant rats near term: a "physiological" animal model of nonthyroidal illness? Endocrinology 127 10-16

Capuco AV, Kahl S, Jack LJAW, Bishop JO and Wallace H (1999) Prolactin and growth hormone stimulation of lactation in mice requires thyroid hormones Proceedings of the Society of Experimental Biology and Medicine 221 345-351

Carón RW and Deis RP (1997) A single dose of mifepristone induces ovulation in pseudopregnant rats Life Sciences 61 1517-1527

Deis RP (1968) The effect of an exteroceptive stimulus on milk ejection in lactating rats Journal of Physiology 197 37-46

Deis RP and Alonso N (1975) Effect of synthetic thyrotrophin releasing factor on prolactin and luteinizing hormone secretion in male and female rats during various reproductive states Journal of Endocrinology 67 425-430

Deis RP, Carrizo DG and Jahn GA (1989) Suckling-induced prolactin release potentiates RU486-induced lactogenesis in pregnant rats Journal of Reproduction and Fertility 87 147-153

de Greef WJ, Voogt JL, Visser TJ, Lamberts SW and van der Schoot P (1987) Control of prolactin release induced by suckling Endocrinology $121316-322$

De Launoit Y and Kiss R (1989) Influence of L-thyroxine, L-triiodothyronine, thyroid stimulating hormone, or estradiol on the cell kinetics of cultured mammary cancer cells In Vitro Cellular and Developmental Biology 25 585-591

Edery M, Houdebine LM, Djiane J and Kelly PA (1984) Studies of beta-casein content of normal and neoplastic rat mammary tissues by a homologous radioimmunoassay Molecular and Cellular Endocrinology 34 145-151

Freeman ME (1994) The neuroendocrine control of the ovarian cycle of the rat. In The Physiology of Reproduction pp 613-658 Eds E Knobil and JD Neill. Raven Press, New York

Fujimoto N, Watanabe H and Ito A (1996) Blockade of the estrogen-induced increase in progesterone receptor caused by propylthiouracil, an antithyroid drug, in a transplantable pituitary tumor in rats Endocrine Journal 43 329-334

Fukuda H, Ohshima K, Mori M, Kobayashi I and Greer MA (1980) Sequential changes in the pituitary-thyroid axis during pregnancy and lactation in the rat Endocrinology 107 1711-1716

Galton VA (1968) Thyroxine metabolism and thyroid function in the pregnant rat Endocrinology 82 282-290

Glinoer D (1997) The regulation of thyroid function in pregnancy: pathways of endocrine adaptation from physiology to pathology Endocrine Reviews 18 404-433

Glinoer D (1998) The systematic screening and management of hypothyroidism and hyperthyroidism during pregnancy Trends in Endocrinology and Metabolism 9 403-411

Gonzalez-Sancho JM, Alvarez-Dolado M, Caelles C and Munoz A (1999) Inhibition of tenascin- $C$ expression in mammary epithelial cells by thyroid hormone Molecular Carcinogenesis 24 99-107

Hagino N (1971) Influence of hypothyroid state on ovulation in rats Endocrinology 88 1332-1336

Hendrich CE and Porterfield SP (1992) Serum growth hormone levels in hypothyroid and $\mathrm{GH}$-treated thyroidectomized rats and their progenies Proceedings of the Society of Experimental Biology and Medicine 201 296-302

Jack LJW, Kahl S, St Germain DL and Capuco AV (1994) Tissue distribution and regulation of $5^{\prime}$-deiodinase processes in lactating rats Journal of Endocrinology 142 205-215

Jahn GA and Deis RP (1991) The involvement of the adrenergic system on the release of prolactin and lactogenesis at the end of pregnancy in the rat Journal of Endocrinology 129 343-350

Jahn GA, Rastrilla AM and Deis RP (1993) Correlation of growth hormone secretion during pregnancy with circulating prolactin in rats Journal of Reproduction and Fertility 98 327-333

Jahn GA, Moya G, Jammes H and Rosato RR (1995) Effect of chronic thyroid hormone treatment on cycling, ovulation, serum reproductive hormones and ovarian $\mathrm{LH}$ and prolactin receptors in rats Endocrine 3 121-127

Kampmann JP and Hansen JM (1981) Clinical pharmacokinetics of antithyroid drugs Clinical Pharmacokinetics 6 401-428

Kuhn NJ and Lowenstein JM (1967) Lactogenesis in the rat. Changes in metabolic parameters at parturition Biochemical Journal 105 995-1002

Li M, Liu X, Robinson G, Bar-Peled U, Wagner KU, Young WS, Henninghausen L and Furth PA (1997) Mammary-derived signals activate programmed cell death during the first stage of mammary gland 
involution Proceedings National Academy of Sciences USA 943425 3430

Marti A, Jaggi R, Vallan C, Ritter PM, Baltzer A, Srinivasan A, Dharmarajan AM and Friss RR (1999) Physiological apoptosis in hormone-dependent tissues: involvement of caspases Cell Death and Differentiation 61190 1200

Mattheij JAM, Swarts JJM, Lokerse P, van Kampen JT and Van der Heide D (1995) Effect of hypothyroidism on the pituitary-gonadal axis in the adult female rat Journal of Endocrinology 146 87-94

Momotani N, Yamashita R, Makino F, Noh JY, Ishikawa N and Ito K (2000) Thyroid function in wholly breast-feeding infants whose mothers take high doses of propylthiouracil Clinical Endocrinology 53 177-181

Mueller GP, Chen HJ and Meites J (1973) In vivo stimulation of prolactin release in the rat by synthetic TRH Proceedings of the Society of Experimental Biology and Medicine 144 613-615

Parrot MW, Johnston ME and Durbin PW (1960) The effects of thyroid and parathyroid deficiency on reproduction in the rat Endocrinology 67 467-483

Peterson M (1994) Thyroid disease and fertility Immunology and Allergy Clinics of North America 14 725-738

Rosato RR, Gimenez MS and Jahn GA (1992) Effects of chronic thyroid hormone administration on pregnancy, lactogenesis and lactation in the rat Acta Endocrinologica 127 547-554

Rosato RR, Jammes H and Jahn GA (1998) Effect of chronic thyroxine treatment on pregnancy in rats: effects on oestrogen, progesterone, prolactin and $\mathrm{GH}$ receptors in uterus, liver and mammary gland Endocrine Research 24 269-284

Rosato RR, Lindenbergh-Kortleve DJ, van Neck JW, Drop S and Jahn GA (2002) Effect of chronic thyroxine treatment on insulin growth factor-I, insulin growth factor-II and insulin-like growth factor binding proteins expression in mammary gland and liver during pregnancy and early lactation in rats European Journal of Endocrinology 146729 739

Rose DP and Mountjoy KG (1983) Influence of thyroidectomy and prolactin suppression on the growth of $N$-nitrosomethylurea-induced rat mammary carcinomas Cancer Research 43 2588-2591

Sarlis NJ, Gourgiotis L, Pucino F and Tolis GJ (2002) Lack of association between Hashimoto thyroidits and breast cancer: a quantitative research synthesis Hormones 1 15-41
Smyth PP (1997) The thyroid and breast cancer: a significant association? Annals of Medicine 29 189-191

Snedecor GW and Cochran WG (1967) Statistical Methods lowa State University Press, lowa

Sumitani S, Kasayama S, Hirose T, Matsumoto K and Sato B (1991) Effects of thyroid hormone on androgen- or basic fibroblast growth factor-induced proliferation of Shionogi carcinoma 115 mouse mammary carcinoma cells in serum-free culture Cancer Research 51 4323-4327

Topper YJ and Freeman CS (1980) Multiple hormone interactions in the developmental biology of the mammary gland Physiological Reviews 60 1049-1106

Varas SM, Muñoz EM, Hapon MB, Aguilera-Merlo CI, Gimenez MS and Jahn GA (2002) Hyperthyroidism and production of precocious involution in the mammary glands of lactating rats Reproduction $\mathbf{1 2 4}$ 691-702

Vermouth $\mathbf{N}$ and Deis RP (1972) Prolactin release induced by prostaglandin $\mathrm{F}_{2 \alpha}$ in pregnant rats Nature 238 248-250

Versloot PM, Gerritsen J, Boogerd L, Schroder-van der Elst JP and van der Heide D (1994) Thyroxine and 3,5,3'-triiodothyronine production, metabolism, and distribution in pregnant rat near term American Journal of Physiology 267 E860-867

Vonderhaar BK (1979) Lactose synthetase activity in mouse mammary glands is controlled by thyroid hormones Journal of Cell Biology 82 675-681

Vonderhaar BK and Greco AE (1982) Effect of thyroid status on development of spontaneous mammary tumors in primiparous $\mathrm{C} 3 \mathrm{H}$ mice Cancer Research 42 4553-4561

Vonderhaar BK, Tang E, Lyster RR and Nascimento MC (1986) Thyroid hormone regulation of epidermal growth factor receptor levels in mouse mammary glands Endocrinology 119 580-585

Vorherr $\mathbf{H}$ (1978) Thyroid disease in relation to breast cancer Klinische Wochenschrift 56 1139-1145

Received 31 March 2003.

First decision 21 May 2003.

Revised manuscript received 5 June 2003.

Accepted 10 June 2003. 